\title{
SRK II formula in the calculation of intraocular lens power
}

\author{
MOHINDER SINGH DANG AND P P SUNDER RAJ \\ From the Department of Ophthalmology, Memorial Hospital, Darlington DL36HX.
}

SUMMARY We studied 400 eyes which underwent cataract extraction with posterior chamber intraocular lens (IOL) implantation to compare the predictive accuracy of various IOL power calculation formulae. The new Sanders-Retzlaff-Kraff (SRK) II formula was more accurate than the original SRK and Binkhorst II formulae. Modification of the A constants used in the SRK II formula to make it 'surgeon specific' improved its performance further; $80 \%$ of the eyes had less than 1 dioptre error and only one eye $(0.3 \%)$ had an error of more than 3 dioptres.

Intraocular lens (IOL) implantation is at present the commonest method of visual rehabilitation after cataract extraction. Successful IOL implantation depends partly on the ability to predict postoperative refraction with accuracy. Numerous IOL power calculation formulae are available. They are either mathematical, based on theoretical optics, ${ }^{1-4}$ empirical, based on statistical regression analysis of a large number of implant patients,,-10 or a combination of the theoretical-empirical approaches. " There is no general consensus as to which approach or which particular formula is the most accurate. ${ }^{1017}$ However, the Sanders-Retzlaff-Kraff (SRK) formula $^{56}$ has become the most widely used for implant power calculation throughout the world. ${ }^{1016-22}$ Sanders et al $^{\prime \prime}$ have recently introduced a new SRK II formula which has been shown to reduce the prediction error of the original SRK formula in short $(<22 \mathrm{~mm})$ and long ( $>24.5 \mathrm{~mm}$ axial length) eyes.

We routinely use the SRK formula to calculate IOL implant power. This study was carried out, firstly, to compare the predictive accuracy of the new SRK II formula with that of the original SRK and Binkhorst II formulae (see Appendix), and secondly improve if possible the results of the SRK II formula by modifying the constants used.

\section{Materials and methods}

This study was performed on 400 consecutive eyes which underwent cataract extraction followed by IOL implantation. All the eyes included in this study

Correspondence to Mr M S Dang, FRCS. had a final corrected visual acuity of $6 / 12$ or better and postoperative astigmatism of less than 2.5 dioptres in cylindrical power.

IOL power was calculated on measurements of axial length and corneal curvature. All axial lengths were measured by applanation (A scan ultrasonography) with the Radionics Medical Oculometer ${ }^{\mathrm{TM}}$ 4100 system with a $10 \mathrm{MHz}$ transducer. Corneal curvature was taken as the average of measurements in two meridia with an Inami BL-1 Keratometer. The power of the IOL implant was calculated by the software program within the ultrasound equipment system.

All the operations were carried out by the same surgeon (MSD). Cataract extraction followed by a posterior chamber IOL (IOLAB 107W modified Sinskey style, $10^{\circ}$ angulated reversed optic lens) in the capsular bag was performed by the 'Intercapsular' technique. ${ }^{23}$

Sutures were selectively cut or loosened in patients at four to six weeks postoperatively if they had a cylindrical power of 2.5 dioptres (D) or more. However, if the desired results were not obtained by this procedure, all the sutures were removed at eight weeks postoperatively. Refractions used in this study were carried out between six and eight weeks postoperatively.

We adopted the approach of Sanders et $a l^{\prime \prime \prime}$ and grouped our data base in subsets of short eyes (axial length less than $22 \mathrm{~mm}$ ) and long eyes (greater than or equal to $24.5 \mathrm{~mm}$ ), with average eyes in between. We derived separate A constants within each subset and used these values in our modification of the SRK II formula. 
The original SRK formula was used to calculate the predicted emmetropic IOL power values for each patient. The deviations of the actual implant power from that predicted were converted to the dioptric spherical equivalent in the spectacle plane by the following formula:

$$
\text { Deviation }=\left(P_{1}-P_{F}\right) \times 1 / C R+R_{S} \text {. }
$$

where $P_{I}$ is the dioptric power of the actual implant used, $\mathrm{P}_{\mathrm{E}}$ is the predicted emmetropic IOL power, $\mathrm{CR}$ is the ratio between the implant and the spectacle plane, and $R_{S}$ is the observed postoperative refraction. We used a $C R$ value of 1.25 for $P_{E}>14 \mathrm{D}$ and 1.00 for $\mathrm{P}_{\mathrm{E}}<14 \mathrm{D}$. $^{112425}$

This process of computing the difference between the actual and predicted postoperative refractive status of each patient was then carried out for the other IOL power calculation formulae under evaluation-Binkhorst II, SRK II, and our modification of the SRK II formula. We assessed the clinical significance rather than the statistical significance ${ }^{26}$ of the difference in predictive accuracy of the above formulae on the basis of the following parameters: mean absolute deviation from emmetropia (in dioptres), standard error of the mean deviation and the distribution of the deviations (number of patients with actual postoperative refraction within 1 or 2 dioptres respectively of the predicted postoperative refraction).

\section{Results}

Our database consisted of 400 eyes with IOL implants. They comprised 65 short eyes (axial length $<22 \mathrm{~mm}$ ), 283 eyes of average axial length (22-24.49 $\mathrm{mm})$, and 52 long eyes ( $\geqslant 24.5 \mathrm{~mm})$.

The A constants we derived after dividing the above groups into subgroups were as follows: Average eyes: 118.4; short eyes: $<20 \mathrm{~mm}-119 \cdot 9,20$ to $<21 \mathrm{~mm}-119 \cdot 5,21$ to $<22 \mathrm{~mm}-119$; long eyes: $24 \cdot 5$ to $<26 \mathrm{~mm}-117 \cdot 3, \geqslant 26 \mathrm{~mm}-117$. Hence we 'personalised' the A constants used in the SRK II formula to make it 'surgeon specific' as shown in Table 1.

Table 1 The surgeon-specific SRK II formula

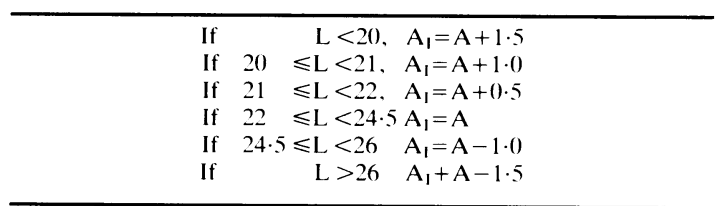

$L$ is the axial length of the eye (in $\mathrm{mm}$ ).

$\mathrm{A}$ is the average $\mathrm{A}$ constant derived by the surgeon ('personalised' $\mathrm{A}$ constant).

$A_{1}$ is the recommended $A$ constant for use in calculating IOL power.
Table 2 Comparison of the predictive accuracy of various IOL power calculation formulae.

\begin{tabular}{|c|c|c|c|c|}
\hline \multirow[t]{2}{*}{ Formula } & \multirow[t]{2}{*}{ Absolute error } & \multicolumn{3}{|c|}{$\begin{array}{l}\text { Distribution of } \\
\text { postoperative refractive } \\
\text { (rror in dioptres: number of } \\
\text { patients (percentage) }\end{array}$} \\
\hline & & $<I D$ & $<2 D$ & $\geqslant 3 \mathrm{D}$ \\
\hline Binkhorst II & $(0.85 \mathrm{D}(0.03)$ & $292(73)$ & $383(96)$ & $4(1 \cdot())$ \\
\hline SRK & $0.84 \mathrm{D}(0.03)$ & $293(73)$ & $380(95)$ & $4(1 \cdot 0)$ \\
\hline SRK II & $(0.82 \mathrm{D}(0 .(03)$ & $312(78)$ & $384(96)$ & $3(0 \cdot 8)$ \\
\hline \multicolumn{5}{|l|}{ 'Personalised' } \\
\hline SRK II & $0.79 \mathrm{D}(0.03)$ & $321(80)$ & $387(97)$ & $1(0 \cdot 3)$ \\
\hline
\end{tabular}

Table 2 shows the overall comparison in the predictive accuracy of different IOL power calculation formulae. All of them performed equally well in the number of cases within an error of 2 dioptres. When the percentage of eyes within $1 \mathrm{D}$ error was considered, SRK II was better than the original SRK and Binkhorst II formulae, with $78 \%$ accuracy. The personalised or surgeon-specific SRK II formula improved this further; $80 \%$ of the eyes had less than 1 $\mathrm{D}$ error and only one case $(0 \cdot 3 \%)$ had an error of more than $3 \mathrm{D}$.

In the 'long eye' group (Table 3 ), the SRK formula performed poorly compared with the SRK II and

Table 3 Comparison of the performance of various $I O L$ power calculation formulae in eyes grouped according to the axial length

\begin{tabular}{|c|c|c|c|c|}
\hline \multirow[t]{2}{*}{ Formula } & \multirow[t]{2}{*}{$\begin{array}{l}\text { Absolute error: } \\
\text { mean (standard } \\
\text { error) }\end{array}$} & \multicolumn{3}{|c|}{$\begin{array}{l}\text { Distribution of postoperative } \\
\text { refractive error in dioptres: } \\
\text { number of patients (percentage) }\end{array}$} \\
\hline & & $<I I)$ & $<2 D$ & $\geqslant 3 \mathrm{D}$ \\
\hline \multicolumn{5}{|l|}{$\begin{array}{l}\text { Short eyes } \\
\quad<22 \mathrm{mn}\end{array}$} \\
\hline Binkhorst II & $1 \cdot 13 \mathrm{D}(0 \cdot 11)$ & $42(6.5)$ & $59(91)$ & $2(3 \cdot 1)$ \\
\hline SRK & $1 \cdot() 8 \mathrm{D}(0 \cdot 10)$ & $41(63)$ & $60(92)$ & $2(3 \cdot 1)$ \\
\hline SRK II & $(0.97 \mathrm{D}(0.09)$ & $51(79)$ & $62(95)$ & $1(1 \cdot 5)$ \\
\hline \multicolumn{5}{|l|}{ 'Personalised' } \\
\hline SRK II & $(0.87 \mathrm{D}(0 .(18)$ & $57(88)$ & $64(98)$ & - \\
\hline \multicolumn{5}{|c|}{$\begin{array}{l}\text { Average eyes }(22 \\
\text { to }<24.5 \mathrm{~mm})\end{array}$} \\
\hline Binkhorst II & $0.80 \mathrm{D}(0 \cdot 3)$ & $2(19(74)$ & $274(97)$ & $1(0 \cdot 4)$ \\
\hline SRK & $(0.78 \mathrm{D}(0.3)$ & $218(77)$ & $272(96)$ & $1(0 \cdot 4)$ \\
\hline SRK II & $(0.78 \mathrm{D}(0.3)$ & $218(77)$ & $272(96)$ & $1(0 \cdot 4)$ \\
\hline \multicolumn{5}{|l|}{ 'Personalised' } \\
\hline SRK II & $(0.78 \mathrm{D}(0.3)$ & $218(77)$ & $272(96)$ & $1(() \cdot 4)$ \\
\hline \multicolumn{5}{|l|}{$\begin{array}{l}\text { Long eyes } \\
\qquad(\geqslant 24.5 \mathrm{~mm})\end{array}$} \\
\hline Binkhorst II & $(0.79 \mathrm{D}(0.07)$ & $41(79)$ & $50(96)$ & $1(1.9)$ \\
\hline SRK & $0.89 \mathrm{D}(0.8)$ & $34(65)$ & $48(92)$ & $1(1.9)$ \\
\hline SRK II & $0.82 \mathrm{D}(0 .(17)$ & $43(83)$ & $50(96)$ & $1(1.9)$ \\
\hline \multicolumn{5}{|l|}{ 'Personalised' } \\
\hline SRK II & $(0.75 \mathrm{D}(0 \cdot() 6)$ & $46(89)$ & $51(98)$ & - \\
\hline
\end{tabular}


Binkhorst II formulae, especially in the percentage of eyes within $1 \mathrm{D}$ error. The personalised SRK II formula produced the best results, with no case having an error of more than $3 \mathrm{D}$.

In the 'short' eye group (Table 3) both the SRK and Binkhorst II formulae predicted relatively inaccurately compared with the SRK II formula, with $35 \%$ or more of the cases having more than $1 \mathrm{D}$ error. The personalised SRK II formula was again better than the SRK II formula: $88 \%$ of the cases achieved less than $1 \mathrm{D}$ error, and no case had an error of more than $3 \mathrm{D}$.

\section{Discussion}

Calculation of the intraocular lens implant power is still a relatively controversial subject. Despite the availability of numerous formulae $e^{1-11}$ none has been proved superior in all clinical situations. ${ }^{10-172+25}$ This is mainly due to the presence of various surgeonspecific variables like the type of keratometer or ultrasound equipment used, style of IOL, and surgical technique adopted. ${ }^{16} 172127$ Some authors have recommended that the ideal solution to this problem is for the individual surgeon to develop his own formula. ${ }^{2 \times 24}$ However, not all ophthalmologists have the time or the resources to do this and hence have to depend on one of the readily available IOL power calculation formulae.

We chose to concentrate on the SRK formula for the following reasons: (1) It is the most widely used formula throughout the world and includes many users in the United Kingdom. ${ }^{17-22}$ (2) Improving this formula will mean more accuracy at no extra expense to the surgeon; some of the available formulae are expensive and would make the existing equipment obsolete. (3) It is a simple and elegant formula, and the constants used can be easily modified to make it surgeon-specific. Such modification has been shown to improve the predictive accuracy of the original SRK formula. ${ }^{17202127}$

The SRK II formula can be calculated with the same equipment and program as that for the original SRK formula. We found it easy to use, since it merely needed appropriate adjustment to the A constant depending on the axial length of the eye under consideration; all other inputs were the same. This adjustment was necessary in $29 \%$ of the eyes which were not of average length.

It is evident from Table 2 that over all the SRK II formula was only marginally better than the SRK and Binkhorst II formulae. This is because the majority of the eyes are of average axial length, where the various IOL calculation formulae predict equally accurately. It is the short eyes or long eyes which usually cause problems in the predictability after calculation of IOL power. In both these groups the SRK II formula was clearly superior to the SRK and Binkhorst II formulae (Table 3).

We had no difficulty in 'personalising' the A constants used in the SRK II formula. This improved its predictive accuracy further (Tables 2 and 3 ). We had to modify the SRK II formula probably because of the difference in the distribution of ocular axial lengths between our data and those of Sanders et al." In our database, more eyes were less than $22 \mathrm{~mm}$ $(16 \%$ versus $8 \%)$ and fewer eyes equal to or greater than $24.5 \mathrm{~mm}(13 \%$ versus $14 \%)$, with our average A constant weighted towards the short eyes as compared with that of Sanders et al. ${ }^{\text {1" }}$ Moreover, the role of the rather ill defined surgeon-specific variables in affecting the performance of IOL power calculation formulae for the individual surgeon is well known. 116172123

Though there is no consensus on this subject, we used CR values of 1.00 for emmetropic IOL powers less than $14 \mathrm{D}$ and 1.25 for emmetropic powers equal to or more than $14 \mathrm{D}$, as has been recommended. ${ }^{11} \geq 2 \geq 5$ This means that a change of one dioptre in IOL power will produce a change in refraction at the spectacle plane of $1.0 \mathrm{D}$ if the emmetropic IOL power is less than $14 \mathrm{D}$ or $0.80 \mathrm{D}$ if the emmetropic power is equal to or more than $14 \mathrm{D}$. This helps the surgeon to calculate mentally and choose an IOL of appropriate power when aiming for a desired amount of ametropia.

Induced corneal astigmatism following cataract surgery is well known. Selective suture cutting or loosening relieved astigmatism induced by tight suturing. No wound leaks or dehiscences occurred in any of our patients. Some patients, however, developed troublesome astigmatism in a different axis. All the sutures were removed in these patients because of our clinical impression that this procedure is better than further selective removal or loosening of the sutures. At present we are reassessing our management of postoperative astigmatism in the light of two recent reports. Firstly, Richards et al $l^{31}$ found that cutting sutures in the early postoperative period is effective for control of astigmatism, but this effect decays with time. In fact, there was no difference at three years between the cases in which sutures had been cut and those in which they had not been cut. Secondly, there is a rapid resolution of astigmatism in the first four months after surgery. ${ }^{31}$

The SRK II formula provides a high degree of predictive accuracy at no extra cost in terms of time or money to the users of the original SRK formula. The constants used can be easily modified by the surgeon to take into account surgeon-specific variables and thus improve its ability to predict IOL power. 


\section{Appendix}

$$
\begin{aligned}
& \text { SRK formula'": } \\
& \mathrm{P}=\mathrm{A}-2.5 \mathrm{~L}_{\mathrm{I}}-0.9 \mathrm{~K} \text {. }
\end{aligned}
$$

Binkhorst II formula solved for IOL power ':

$$
P=\frac{1000 N_{2}\left\{\left(1000-V R_{S}\right)\left(N_{2} r-\left(\left(N_{1}-1\right)\right) L_{2}\right)-r R_{S} L_{2}\right\}}{\left(L_{2}-D\right)\left\{\left(1000-V R_{S}\right)\left(N_{2} r-\left(\left(N_{1}-1\right)\right) D\right)-r R_{S} D\right\}}
$$

where

$P=$ Calculated $I O L$ power

$A=A$ constant used with the original SRK formula.

$A_{1}=$ Recommended $A$ constant for use in calculating IOL power.

$\mathrm{L}_{\mathrm{l}}=$ Axial length of the eye (in $\mathrm{mm}$ ) preoperatively.

$\mathrm{L}_{2}=$ Axial length of the eye (in $\mathrm{mm}$ ) postoperatively.

$\mathbf{K}=$ Corneal power in dioptres.

$r=$ Corneal power in millimetres radius.

$N_{1}=$ Refractive index of aqueous and vitreous (1-336).

$\mathrm{N}_{2}=$ Refractive index of cornea (1.333).

$\mathrm{V}=$ Vertex distance $(12 \mathrm{~mm})$.

$\mathrm{D}=$ Anterior chamber depth (in $\mathrm{mm}$ ) postoperatively.

$\mathrm{R}_{\mathrm{S}}=$ Postoperative spectacle refraction.

Our thanks to Mr J M Salter and staff of our Medical Records Department for the patient case notes; Mrs B Mais, librarian, for her invaluable references; and Dr A Downs for his assistance with the calculations.

\section{References}

1 Colenbrander MC. Calculation of the power of an iris clip lens for distance vision. Br J Ophthalmol 1973: 57: 735-40.

2 Hoffer KJ. Intra-ocular lens calculation: the problem of the short eye. Ophthalmic Surg 1981; 12: 269-72.

3 Binkhorst RD. Intraocular lens power calculation manual-a guide to the authors. TI-58/51. Intraocular lens power module, 2nd ed. New York: Binkhorst, 1981.

4 Shammas HJF. The fudged formula for intraocular lens power calculations. J Am Intraocul Implant Soc 1982: 8: 350-2.

5 Retzlaff J. A new intraocular lens calculation formula. $J \mathrm{Am}$ Intraocul Implant Soc 1980; 6: 148-52.

6 Sanders DR, Kraff MC. Improvement of intraocular lens power calculation using empirical data. J Am Intraocul Implant Soc 1980; 6: 263-7.

7 Gills P. Minimising post-operative refractive error. CLAO J 1980; 6: 56-9.

8 Thompson JT, Maumenee AE, Baker CC. A new posterior chamber intraocular lens formula for axial myopes. Ophthalmology 1984: 91: 485-8.

9 Donzis PB, Kastl PR, Gordon RA. An intraocular lens for short, normal and long eyes, $C L A O J$ 1985: 11: 95-8.
10 Sanders DR, Retzlaff J. Kraff MC. Comparison of the SRK II formula and other second generation formulae. $J$ Cataract Refract Surg 1988: 14: 136-41.

11 Holladay JT. Prager TC, Chandler TY, et al. A three part system for refining intraocular lens power calculations. J Cataract Refract Surg 1988: 14: 17-24.

12 Sanders DR, Retzlaff J, Kraff MC, et al. Comparison of the accuracy of the Binkhorst. Colenbrander and SRK implant power prediction. J Am Intraocul Implant Soc 1981: 7: 337-40.

13 Hoffer KJ. Pre-operative cataract evaluation: intraocular lens power calculation. Int Ophthalmol Clin 1982: 11: 37-75.

14 Hillman JS. Intraocular lens power calculation - the selection of formula. Trans Ophthalmol Soc UK 1983; 103: 577-9.

15 Richards SC. OIson RJ, Richards WL. et al. Clinical evaluation of six intraocular lens calculation formulae. $J \mathrm{Am}$ Intraocul Implant Soc 1985; 11: 153-8.

16 Holliday BL. Calculation of intraocular lens power-results in practice. Trans Ophthalmol Soc UK 1986; 105: 435-40.

17 Singh-Dang M. Sunder Raj PP. Calculation of the power of posterior chamber intraocular lenses. Afro-Asian J Ophthalmol (in press).

18 Percival P. Lens power calculation: is it necessary? Trans Ophthalmol Soc UK 1983; 103: 577-9.

19 Menezo JL, Chaques V, Harts M. The SRK regression formula in calculating the dioptric power of the intraocular lens. $\mathrm{Br} \mathrm{J}$ Ophthalmol 1984; 68: 235-7.

20 Tutton MK. Intraocular lens power calculations using the SRK formula: a clinical study. Trans Ophthalmol Soc UK 1985; 104: 675-80.

21 Longstaff S. Factors affecting intraocular lens power calculations. Trans Ophthalmol Soc UK 1986; 105: 642-5.

22 Singh M, Dahalan A. Significance of intraocular lens power calculation. Br J Ophthalmol 1987: 71: 850-3.

23 Lim ASM. Endocapsular cataract extraction. Implants in Ophthalmology 1987; 1: 52-4.

24 Holladay JT, Prager TC, Christie B. Intraocular lens power calculation. J Cataract Refract Surg 1988; 14: 453-4.

25 Sanders DR, Retzlaff JA, Kraff MC. Intraocular lens power calculation. J Cataract Refract Surg 1988; 14: 454-6.

26 Bourne WM. 'No statistically significant difference', so what? (Editorial.) Arch Ophthalmol 1987; 105: 40-1.

27 Retzlaff J, Sanders DR, Kraff MC. A manual of implant power calculation. Oregon: Medford, 1982.

28 Thall EH, Reinhart WJ, Sabol D. Linear regression software for intraocular lens implant power calculation. Am J Ophthalmol 1986; 101: 597-9.

29 McEwan JR, Cinotti DJ, Maltzmann BA. An intraocular lens power calculation for the IBM PC and PC Jnr computers using input variable selection. $J$ Am Intraocul Implant Soc 1985; 11: 498-503.

30 Richards SC, Brodstein RS, Richards WL, Olson RJ, Combe $\mathrm{PH}$, Crowell KE. Long-term course of surgically induced astigmatism. J Cataract Refract Surg 1988; 14: 270-6.

31 Cory CC. Prevention and treatment of post-implantation astigmatism. J Cataract Refract Surg 1989; 15: 58-60).

Accepted for publication 3 April 1989. 